\title{
Same-Day Imaging Using Small Proteins: Clinical Experience and Translational Prospects in Oncology
}

\author{
Ahmet Krasniqi ${ }^{1}$, Matthias D’Huyvetter ${ }^{1}$, Nick Devoogdt ${ }^{1}$, Fredrik Y. Frejd ${ }^{2,3}$, Jens Sörensen $^{4,5}$, Anna Orlova ${ }^{6}$, \\ Marleen Keyaerts*1,7, and Vladimir Tolmachev*3 \\ ${ }^{I}$ In Vivo Cellular and Molecular Imaging Laboratory (ICMI), VUB, Brussels, Belgium; ${ }^{2}$ Affibody AB, Solna, Sweden; ${ }^{3}$ Department of \\ Immunology, Genetics and Pathology, Uppsala University, Uppsala, Sweden; ${ }^{4}$ Nuclear Medicine and PET, Department of Surgical \\ Sciences, Uppsala University, Uppsala, Sweden; ${ }^{5}$ Medical Imaging Centre, Uppsala University Hospital, Uppsala, Sweden; \\ ${ }^{6}$ Department of Medicinal Chemistry, Uppsala University, Uppsala, Sweden; and ${ }^{7}$ Nuclear Medicine Department, UZ Brussel, \\ Brussels, Belgium
}

Imaging of expression of therapeutic targets may enable stratification of patients for targeted treatments. The use of small radiolabeled probes based on the heavy-chain variable region of heavy-chain-only immunoglobulins or nonimmunoglobulin scaffolds permits rapid localization of radiotracers in tumors and rapid clearance from normal tissues. This makes high-contrast imaging possible on the day of injection. This mini review focuses on small proteins for radionuclide-based imaging that would allow same-day imaging, with the emphasis on clinical applications and promising preclinical developments within the field of oncology.

Key Words: scaffold proteins; affibody; nanobody; radionuclide molecular imaging

J Nucl Med 2018; 59:885-891

DOI: 10.2967/jnumed.117.199901

$\mathbf{T}$ he discovery of key pathways that drive disease progression has led to the identification of new targetable molecules. When such molecules are located on the cell membrane or in the extracellular space, monoclonal antibodies (mAbs) can often block or activate these pathways. These mAbs typically show a slow systemic clearance, allowing a triweekly treatment regimen. Several mAbs have been used for PET imaging - the so-called immuno-PET approach (1). This approach allows study of the pharmacokinetics and receptor occupancy of the therapeutics, as well as the presence and accessibility of the molecular target in the individual patient. Because these mAbs are produced in large quantities by the pharmaceutical industry as therapeutics, they are typically available as a targeting moiety for the development of an imaging agent at very low cost. A

Received Dec. 22, 2017; revision accepted Mar. 6, 2018.

For correspondence or reprints contact: Marleen Keyaerts, ICMI, VUB, Laarbeeklaan 103, B-1090 Brussels, Belgium.

E-mail: marleen.keyaerts@vub.ac.be

${ }^{*}$ Contributed equally to this work.

Published online Mar. 15, 2018.

COPYRIGHT (C 2018 by the Society of Nuclear Medicine and Molecular Imaging. major disadvantage is the long blood circulation time, with half-lives of up to $28 \mathrm{~d}$, requiring delayed scanning time points typically between 4 and $6 \mathrm{~d}$ (Fig. 1A). Even at that time, appreciable quantities of the tracer remain in the blood, resulting in low sensitivity due to high background uptake and low specificity due to an enhanced permeability and retention effect, especially for targets with a low expression level.

To overcome the slow clearance and extravasation, mAbs have been engineered to smaller fragments such as antigenbinding, variable, and single-chain variable fragments; diabodies; and minibodies (2), with a molecular weight of 25-110 kDa. Although this size reduction increases the clearance rate of nonbound tracers, the clearance and extravasation rates remain overall too low to allow same-day imaging with sufficient contrast. Attractive alternative targeting proteins, with a further reduction in size, are Camelid single-domain antibody fragments (sdAbs) and several nonimmunoglobulin protein scaffolds such as Affibody molecules (Affibody AB), anticalins, designed ankyrin repeat proteins (DARPins; Molecular Partners AG), and fibronectin type III (FN3, Adnectin; Adnexus) (Fig. 2; Table 1) (3). Their low molecular weight enables fast penetration in tumor tissues, and their lack of a fragment crystallizable region further improves clearance. They allow a same-day imaging approach, much like the current practice for ${ }^{18} \mathrm{~F}-\mathrm{FDG}$ PET, and their application results in a 4 to 6-fold lower radiation exposure than for immuno-PET, making them attractive for routine use. This approach is promising for assessing target expression levels in individual patients to identify those who will likely benefit from targeted treatments.

\section{GENERATION AND TYPICAL CHARACTERISTICS OF SMALL PROTEINS}

sdAbs, also referred to as Nanobodies (Ablynx), represent the smallest functional antibody fragments $(12-15 \mathrm{kDa})$, consisting of the heavy-chain variable region of an immunoglobulin type that is naturally present in Camelidae. sdAbs are typically highly stable and bind antigens quickly and with 


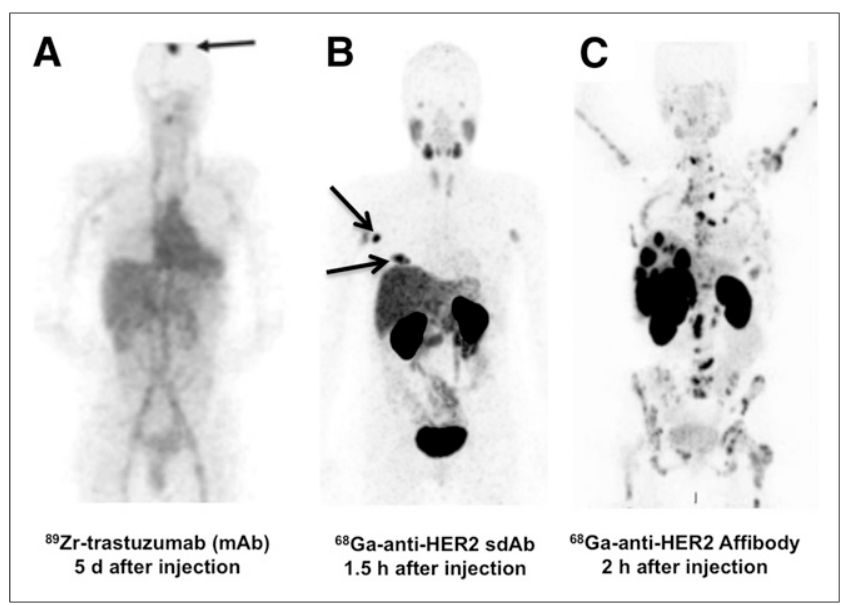

FIGURE 1. Maximum-intensity-projection PET images from patients with metastatic HER2-positive breast cancer, imaged with $m A b$ trastuzumab (A), antibody-derived sdAb (B), or scaffold protein Affibody molecule $(\mathrm{C})$ at various times after injection. Arrows indicate tumor lesions. (Adapted from $(7,21,42)$ and with permission of (42).)

high specificity and affinity. Because of their small size, sdAbs show improved tissue penetration compared with mAbs (4). sdAbs are generated by immunizing camelids with the antigen of choice. The sdAb gene fragments are amplified from isolated lymphocytes, providing a library of potential binders. Affinity-matured target-specific sdAbs are selected via protein display and biopanning and are finally produced in microbial hosts.

Besides antibody fragments, which are derived from different types of antibody classes, different scaffold proteins have also been engineered as small imaging probes (5). Scaffold proteins fall into 2 structural classes. The first is domain-sized compounds (6-20 kDa) such as Affibody (Affibody, Inc.) molecules, albumin-binding domain-derived affinity proteins (ADAPTs), Affilin scaffold proteins (Scil Proteins $\mathrm{GmbH}$ ), Anticalins (Pieris, Inc.), Atrimer trivalent proteins (Anaphore, Inc.), DARPins (Dyax, Inc., Shire Inc.), FN3 scaffolds (Molecular Partners, Inc.), Fynomer platforms (Janssen), Kunitz domains, or Pronectin (Protelica), FN3based sequences (Protelica, Inc.). The second structural class of scaffold protein comprises constrained peptides (2-4 kDa) such as vimers (Avimers [Avidia, Inc., now Amgen]), bicyclic peptides (Bicycle Therapeutics, Inc.), and cystine knot peptides (3). For both classes of scaffold protein, a library of potential binders is typically generated by random or targeted mutagenesis of the parent scaffold protein at residues that are not essential for protein folding. From this, targetspecific binders are selected via phage display, yeast surface display, or ribosome/messenger RNA display. Most sdAbs and engineered scaffold proteins are easily produced in microbial systems, are stable and soluble, and show good binding affinity and specificity (3). So far, several sdAbs and scaffold proteins, selected against different targets, have been used as probes for SPECT and PET imaging $(4,5)$.

\section{SDABS IN RADIONUCLIDE IMAGING}

sdAbs have been successfully applied as probes for radionuclide imaging, of which the human epidermal growth factor receptor (HER2)-targeting sdAbs are most dominantly explored. HER2 is an interesting therapeutic target, as it is overexpressed in several types of cancer, including breast, ovarian, and gastric. The ${ }^{68} \mathrm{Ga}$-labeled HER2-targeting sdAb 2Rs15d enabled high-contrast PET imaging of HER2-positive breast cancer at $1 \mathrm{~h}$ after injection in SKOV-3 xenografts (tumor-to-blood ratio, $29 \pm 8$ ) (6). A good manufacturing practice-grade version was evaluated in a phase I PET study in HER2-positive breast cancer patients (Fig. 1B). The compound was safe, with fast urinary clearance, resulting in a biologic half-life of $1 \mathrm{~h}$ and only $10 \%$ of injected activity remaining in the blood at $1 \mathrm{~h}$ after injection. Biodistribution data showed background uptake in the liver, kidneys, and to a lesser extent bowel and salivary glands. Uptake was high in both primary HER2-positive tumors and metastasis, with standardized uptake value (SUVmean) of up to 11.8 and 6.0, respectively, at $1 \mathrm{~h}$ after injection (Fig. 1B). The effective dose was $0.043 \mathrm{mSv} / \mathrm{MBq}$, resulting in an average of $4.6 \mathrm{mSv}$ per patient, with the critical organ being the urinary bladder wall (0.406 mGy/MBq) (7). The same HER2-targeting sdAb was also ${ }^{18} \mathrm{~F}$-labeled and tested preclinically, with a high tumor-toblood ratio (13 \pm 2 as early as $1 \mathrm{~h}$ after injection). Uptake in the kidneys was, however, only half that measured for ${ }^{68} \mathrm{Ga}-$ labeled $2 \mathrm{Rs} 15 \mathrm{~d}(8)$ and thus might further decrease the radiation exposure. Finally, 2Rs15d was successfully radiolabeled with ${ }^{131}$ I and showed superior tumor uptake and remarkably low kidney retention in HER2-positive tumor xenografted mice (9). Consequently, this version is now being evaluated as a theranostic drug in a first clinical breast cancer trial (NCT02683083). Another HER2-targeting sdAb, 5F7, was radiolabeled with both ${ }^{18} \mathrm{~F}$ and ${ }^{125} \mathrm{I}$ and also demonstrated high-contrast imaging in preclinical studies (10-12).

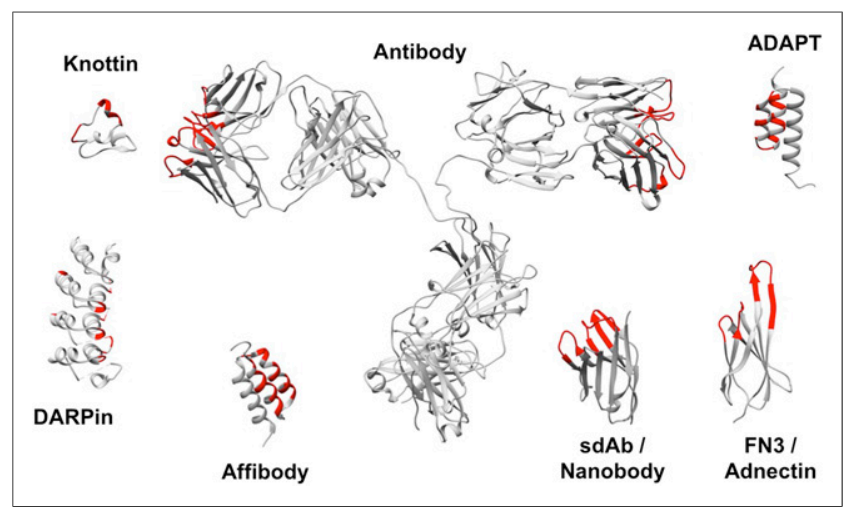

FIGURE 2. Schematic illustration of structures of various targeting vehicles discussed in this review. Most frequent variable stretches and residues are colored red. Structures are sized relative to each other. Representative protein-data-bank files were retrieved from Research Collaboratory for Structural Bioinformatics Protein Data Bank and manipulated using Chimera software: 1IGT (Antibody), 5MY6 (sdAb/Nanobody), 2KZJ (Affibody), 4HRM (DARPin), 2N8B (Knottin), 3QWQ (FN3/Adnectin), and 1GJT (ADAPT). 
TABLE 1

Overview of Radioactively Labeled Targeting Proteins That Have Been Used In Vivo for Same-Day Imaging in Last 5 Years

\begin{tabular}{|c|c|c|c|c|c|c|c|}
\hline Type & Parent protein & Target & Compound name & Radionuclide & $\begin{array}{c}\text { Stage of } \\
\text { development }\end{array}$ & $\begin{array}{c}\text { Tumor-to-blood } \\
\text { ratio* }\end{array}$ & Study \\
\hline \multirow[t]{6}{*}{ ADAPT } & $\begin{array}{l}\text { Albumin-binding domain } \\
\text { of streptococcal } \\
\text { protein G }\end{array}$ & HER2 & $\mathrm{C}-(\mathrm{HE})_{3}$-ADAPT6 & ${ }^{68} \mathrm{Ga}$ & Preclinical & $17 \pm 2(1 \mathrm{~h})$ & (39) \\
\hline & & & $\mathrm{C}-(\mathrm{HE})_{3}-\mathrm{ADAPT} 6$ & ${ }^{111} \ln$ & Preclinical & $43 \pm 11(1 \mathrm{~h})$ & (39) \\
\hline & & & Cys $^{59}$-(HE)3DANS-ADAPT6 & ${ }^{111}$ In & Preclinical & $277 \pm 35(4 \mathrm{~h})$ & $(40)$ \\
\hline & & & Cys ${ }^{59}$-(HE)3DANS-ADAPT6 & 125 & Preclinical & $53 \pm 10(4 \mathrm{~h})$ & $(40)$ \\
\hline & & & 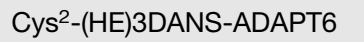 & $111 / n$ & Preclinical & $254 \pm 37(4 \mathrm{~h})$ & $(40)$ \\
\hline & & & Cys $^{2}-(\mathrm{HE}) 3 \mathrm{DANS}-\mathrm{ADAPT} 6$ & 125 & Preclinical & $61 \pm 14(4 \mathrm{~h})$ & $(40)$ \\
\hline \multirow[t]{2}{*}{ Adnectin } & $\begin{array}{l}\text { 10th domain of } \\
\text { human FN3 }\end{array}$ & CD20 & $\mathrm{FN} 3_{\mathrm{CD} 20}$ & ${ }^{64} \mathrm{Cu}$ & Preclinical & $4(24 \mathrm{~h})$ & (37) \\
\hline & & PD-L1 & BMS-986192 & ${ }^{18} \mathrm{~F}$ & Preclinical & $\sim 2(2 \mathrm{~h})$ & (38) \\
\hline \multirow[t]{13}{*}{$\begin{array}{l}\text { Affibody } \\
\text { molecule }\end{array}$} & $\begin{array}{l}\text { Z-domain of } \\
\text { staphylococcal } \\
\text { protein A }\end{array}$ & HER2 & ABY-025 & ${ }^{68} \mathrm{Ga}$ & Clinical & ND & $(21)$ \\
\hline & & & & $111 / n$ & Clinical & ND & $(20)$ \\
\hline & & & ZHER2:V2 & ${ }^{188} \mathrm{Re}$ & Preclinical & $160(8 \mathrm{~h})$ & (24) \\
\hline & & HER3 & Z08698 & $111 / n$ & Preclinical & $12 \pm 3(4 \mathrm{~h})$ & (29) \\
\hline & & & & ${ }^{68} \mathrm{Ga}$ & Preclinical & $25 \pm 6(3 \mathrm{~h})$ & (29) \\
\hline & & & Z08699 & 99mTc & Preclinical & $7 \pm 3(4 h)$ & (29) \\
\hline & & IGF-1R & ZIGF1R:4551 & 99mTc & Preclinical & $4.4 \pm 0.3(8 h)$ & (28) \\
\hline & & EGFR & ZEGFR:2377 & ${ }^{68} \mathrm{Ga}$ & Preclinical & $7 \pm 2(3 \mathrm{~h})$ & $(43)$ \\
\hline & & & & ${ }^{57 / 55} \mathrm{Co}$ & Preclinical & $12 \pm 2(3 \mathrm{~h})$ & (43) \\
\hline & & CAIX & ZCAIX:2 & 99mTc & Preclinical & $44 \pm 7(4 \mathrm{~h})$ & $(30)$ \\
\hline & & & ZCAIX:4 & $125 \mid$ & Preclinical & $23 \pm 3(4 h)$ & (30) \\
\hline & & PDGFR $\beta$ & Z09591 & ${ }^{68} \mathrm{Ga}$ & Preclinical & $8 \pm 3(2 h)$ & (31) \\
\hline & & PD-L1 & $Z_{\mathrm{PD}-\mathrm{L} 1 \_1}$ & ${ }^{18} \mathrm{~F}$ & Preclinical & $5.3(1.5 \mathrm{~h})$ & (32) \\
\hline \multirow[t]{2}{*}{ DARPin } & $\begin{array}{l}\text { Natural ankyrin } \\
\text { repeat domains }\end{array}$ & HER2 & G3 & 125 & Preclinical & $4 \pm 3(4 h)$ & (36) \\
\hline & & & & ${ }^{111}$ In & Preclinical & $174 \pm 26(4 h)$ & (36) \\
\hline \multirow[t]{3}{*}{ Knottin } & Inhibitor cystine-knots & $a_{v} \beta_{6}$ & $\mathrm{~S}_{0} 2$ & ${ }^{64} \mathrm{Cu}$ & Preclinical & $10 \pm 6(1 \mathrm{~h})$ & (33) \\
\hline & & $\alpha_{v} \beta_{3}$ & 7c & $111 / n$ & Preclinical & $9 \pm 3(0.5 \mathrm{~h})$ & (34) \\
\hline & & & $3-4 A$ & ${ }^{18} \mathrm{~F}$ & Preclinical & $6 \pm 1(0.5 \mathrm{~h})$ & (35) \\
\hline \multirow[t]{13}{*}{ sdAbs } & $\begin{array}{l}\text { Heavy-chain-only } \\
\text { antibodies }\end{array}$ & HER2 & 2Rs15d & ${ }^{18} \mathrm{~F}$ & Preclinical & $13 \pm 2(1 \mathrm{~h})$ & (8) \\
\hline & & & & ${ }^{68} \mathrm{Ga}$ & Preclinical & $14 \pm 3(1 \mathrm{~h})$ & (6) \\
\hline & & & & & Clinical & ND & (7) \\
\hline & & & & $131 \mid$ & Preclinical & $\sim 25$ (1 h) & (9) \\
\hline & & & $5 \mathrm{~F} 7$ & ${ }^{18} \mathrm{~F}$ & Preclinical & $47 \pm 13(2 h)$ & (10) \\
\hline & & & 5F7GGC & $131 \mid$ & Preclinical & $11 \pm 2(1 \mathrm{~h})$ & (12) \\
\hline & & MMR & 3.49 & ${ }^{18} \mathrm{~F}$ & Preclinical & $\sim 2(3 \mathrm{~h})$ & $(17)$ \\
\hline & & & $\mathrm{cl} 1$ & 99mTc & Preclinical & 20-30 (3 h) & $(16)$ \\
\hline & & CD20 & 9079 & ${ }^{68} \mathrm{Ga}$ & Preclinical & $\sim 4(1.5 \mathrm{~h})$ & (15) \\
\hline & & PSMA & JVZ-007 & 111 In & Preclinical & $48 \pm 5(3 \mathrm{~h})$ & (14) \\
\hline & & & PSMA30 & 99mTc & Preclinical & $9 \pm 1(1.5 \mathrm{~h})$ & (13) \\
\hline & & PD-L1 & C3 & $99 \mathrm{mTc}$ & Preclinical & $\sim 7(1.5 \mathrm{~h})$ & (18) \\
\hline & & & E2 & 99mTc & Preclinical & $\sim 8(1.5 \mathrm{~h})$ & (18) \\
\hline
\end{tabular}




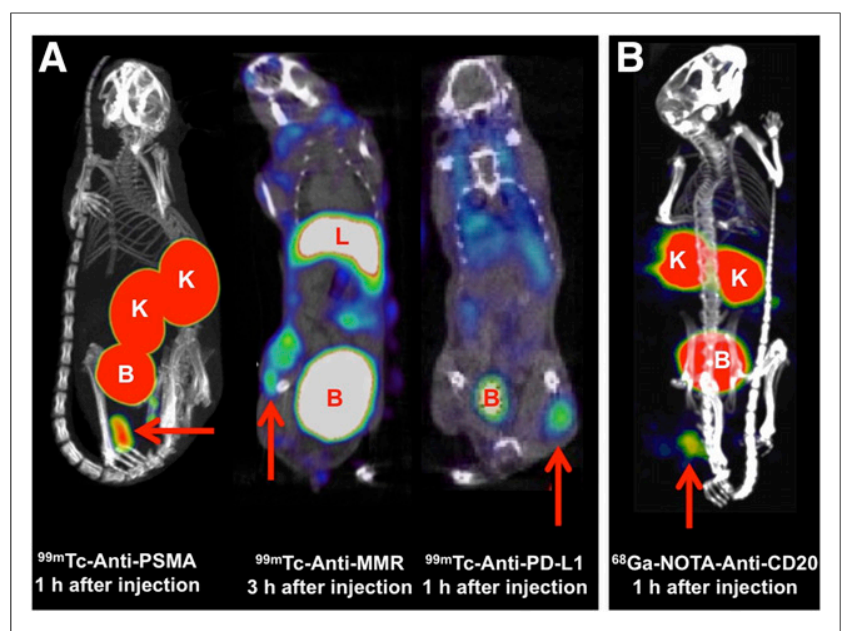

FIGURE 3. SPECT/CT (A) and PET/CT (B) images using sdAbbased tracers in mouse models, showing specific uptake in positive tumor models (arrows). (Adapted from $(13,15,16,18)$ and with permission of (13).) $\mathrm{B}=$ bladder; $\mathrm{K}=$ kidney; $\mathrm{L}=$ liver.

A promising target is the prostate-specific membrane antigen (PSMA), as it is expressed on virtually all metastatic prostate cancers. A PSMA-targeted sdAb (PSMA30) radiolabeled with ${ }^{99 \mathrm{~m}} \mathrm{Tc}$ demonstrated fast and specific uptake in PSMA-positive xenografts (tumor-to-blood ratio of 8.7 at 90 min after injection) (Fig. 3A (13)). Another PSMAtargeting sdAb (JVZ-007) was labeled with ${ }^{111}$ In for SPECT/ $\mathrm{CT}$ imaging. Excellent tumor targeting as early as $3 \mathrm{~h}$ after injection was observed (tumor-to-blood ratio of $48 \pm 5$ ), in the absence of nonspecific uptake (14). Given the current success of clinical imaging using the available PSMAbinding peptides, the question remains of whether these sdAbs have enough added value to bring them to the clinic.

CD20 is expressed in over $90 \%$ of B-cell non-Hodgkin lymphomas and is clinically used for targeted radionuclide therapy with mAbs $\left({ }^{90}\right.$ Y-ibritumomab [Zevalin; Spectrum Pharmaceuticals, Inc.]). Recently, Krasniqi et al. selected a lead CD20-targeting sdAb 9079 and confirmed its potential for same-day PET imaging in a preclinical model (tumorto-blood ratio of approximately 4) (Fig. 3B (15)).

Traditionally, targets selected for molecular imaging and therapy were those overexpressed on the tumor cells themselves. More recently, interest has been raised about targets expressed on the tumor stroma since they can play important roles in tumor angiogenesis, invasion, and immune escape. Such targets are typically less abundantly present in the tumor, which demands a sensitive and very specific technique. It is expected that tracers with slow clearance will not be able to accurately discern such expression from remaining background signals, making the use of sdAb and scaffold proteins the ideal choice. A promising sdAb is one that targets the macrophage mannose receptor (MMR). MMR is highly expressed on protumorigenic tumor-associated macrophages, which play an important role in tumor growth, tumor angiogenesis, metastasis, and immune suppression. Being able to visualize and quantify the presence of MMR (and thus tumor-associated macrophages) in tumor tissue might be a helpful prognostic tool for the treatment of cancer. To this end, Movahedi et al. selected and preclinically validated a lead anti-MMR sdAb (Fig. 3A (16)). A ${ }^{18}$ F-labeled variant was successfully developed as a PET tracer for MMR expression in mice (17), confirming its potential for clinical translation.

Other promising targets within tumor stroma are the immune checkpoints. Success with immune checkpoint blockade with cytotoxic T-lymphocyte-associated protein-4 and programmed death 1 or programmed death ligand 1 (PD-L1) antibody therapy has, however, been seen in only a subset of all cancer patients. Biomarker imaging might help to select patients for such therapies. Anti-PD-L1 sdAbs were developed that could allow the assessment of PD-L1 expression in the tumor microenvironment (Fig. 3A) $(18,19)$.

\section{AFFIBODY MOLECULES IN RADIONUCLIDE IMAGING}

HER2-targeting Affibody molecules were the first scaffold proteins evaluated for radionuclide molecular imaging. The second-generation Affibody molecule ABY-025 labeled with ${ }^{111} \mathrm{In}$ for SPECT imaging and ${ }^{68} \mathrm{Ga}$ for PET imaging were evaluated in phase I/II clinical studies for assessment of HER2 expression in breast cancer metastases (Fig. 1C) $(20,21)$. ABY-025 was found to be safe in humans, and no anti-Affibody antibodies were found after repeated administration. The effective radiation doses were $0.15 \pm 0.02 \mathrm{mSv} / \mathrm{MBq}$ (21 mSv/patient) for ${ }^{111} \mathrm{In}$ and $0.028 \pm 0.003 \mathrm{mSv} / \mathrm{MBq}$ (5.6 mSv/patient) for ${ }^{68} \mathrm{Ga}(20,22)$. Injection of $500 \mu \mathrm{g}$ of ${ }^{68} \mathrm{Ga}-\mathrm{ABY}-025$ provided better sensitivity and specificity than $100 \mu \mathrm{g}$, mainly because of reduced retention in the liver (21). Comparison with immunohistochemical staining of biopsy material demonstrated that the measurement of the maximal uptake value at 2-4 h after injection permits clear discrimination between metastases with $3+$ and $2+$ levels of HER2 expression (21). Furthermore, the spleen can be used as an within-image reference tissue to calculate tumorto-spleen ratios, permitting a simple and robust discrimination between metastases with high and low HER2 expression using both PET and SPECT (23) and thus making the diagnosis independent of external hardware calibrations.

High renal reabsorption of Affibody molecules complicates their use for radionuclide therapy. However, internalization of anti-HER2 Affibody molecules is slow after binding to malignant cells but rapid in proximal tubuli. The peptidebased chelator GGGC provides nonresidualizing ${ }^{188}$ Re labeling, thereby resulting in good tumor retention but rapid washout from kidneys (24). Extrapolation to humans suggests that the absorbed dose to tumors would exceed that to the kidney by approximately 3.4-fold. An alternative might be an Affibodybased pretargeting. Two approaches were evaluated: one mediated by a bioorthogonal reaction between transcyclooctene and tetrazine (25) and another mediated by an interaction between 2 complementary peptide nucleic acids (26). Both methodologies provided appreciably higher uptake of radiometals in tumors than in kidneys, with the peptide nucleic acid-mediated approach resulting in better tumor retention. 
Resistance to trastuzumab therapy may be associated with overexpression of HER3 and insulin-like growth factor type 1 receptor (IGF-1R) (27). Imaging of an emerging expression of these receptors might suggest an onset of resistance and a need to modify treatment. Expression of these receptors is also essential in other malignancies (e.g., prostate and ovarian carcinomas), and multiple therapeutics targeting HER3 or IGF-1R are under development. A challenge in imaging of both receptors is a modest expression level in malignant cells (typically below 40,000 receptors per cell) and expression in normal tissues. Affibody molecules were selected for both molecular targets. To mimic the clinical situation, binders with approximately equal affinity to human and murine receptors were generated. An anti-IGF-1R Affibody molecule, ZIGF1R:4551, was labeled using ${ }^{99 \mathrm{~m}} \mathrm{Tc}(\mathrm{CO})_{3}$ and demonstrated receptor-specific uptake in both IGF-1Rexpressing tumors and IGF-1R-expressing tissues (Fig. 4A) (28). An anti-HER3 Affibody molecule, Z08698, with affinity of $50 \mathrm{pM}$, was previously labeled with ${ }^{111} \mathrm{In}$ and ${ }^{99 \mathrm{~m}} \mathrm{Tc}$ for SPECT imaging. To enable straightforward quantification, HEHEHE-Z08698-NOTA was labeled with positron-emitting ${ }^{68} \mathrm{Ga}$, showing accumulation in tumor xenografts that was proportional to HER3 expression level (Fig. 4B) (29).

Epidermal growth factor receptor (EGFR) is the molecular target for several mAbs and tyrosine kinase inhibitors. Detection of overexpression may help to predict outcomes
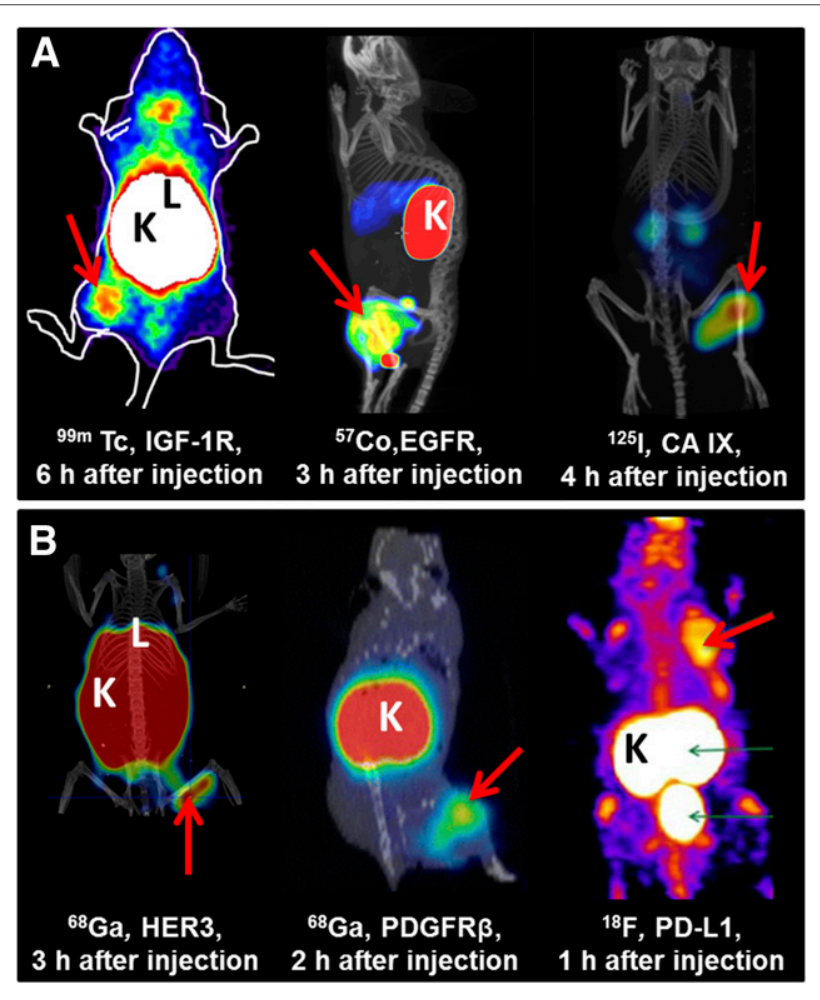

FIGURE 4. $\quad \mathrm{y}$-camera or SPECT/CT (A) and PET/CT (B) imaging using Affibody molecule-based tracers in mice, showing uptake in positive tumor models (arrows). (Rightmost image of $A$ and center image of $B$ adapted from $(28-32,43)$ and with permission of $(28,30,31)$.) $\mathrm{K}=$ kidney; $\mathrm{L}=$ liver. for some treatment regimens for non-small cell lung cancer and head-and-neck squamous cell carcinoma. One of the challenges in imaging EGFR expression is that it is expressed in liver and some other tissues. ZEGFR:2377, having equal affinity to murine and human EGFR (dissociation constant, 0.8-0.9 $\mathrm{nM}$ ), was selected, and an injection of 30-50 $\mu \mathrm{g}$ partially saturated receptors in healthy tissues but not in tumors. Labeling of DOTA-ZEGFR:2377 with ${ }^{68} \mathrm{Ga}$ and ${ }^{57 / 55} \mathrm{Co}$ was assessed. Evaluation of conjugates in A431 xenografts demonstrated that labeling of ZEGFR:2377 with ${ }^{57 / 55}$ Co provided significantly higher tumor-to-organ ratios than did labeling with ${ }^{68} \mathrm{Ga}$ (43). Importantly, a tumor-to-liver ratio of $3.1 \pm 0.5$ ( $3 \mathrm{~h}$ after injection) was obtained (Fig. 4A).

Carbonic anhydrase IX (CAIX) is overexpressed by hypoxic cells, and imaging of CAIX expression may be used to identify radioresistant hypoxic tumors. In addition, CAIX is expressed by normoxic renal cell carcinoma and may be used to distinguish between malignant and benign renal tumors. A panel of anti-CAIX Affibody molecules labeled with ${ }^{99 \mathrm{~m}} \mathrm{Tc}$ and ${ }^{125} \mathrm{I}$ was evaluated in SK-RC-52 renal cell carcinoma

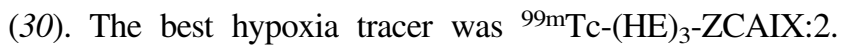
${ }^{125}$ I-ZCAIX:4 was best suited for imaging of renal cell carcinoma, with a tumor-to-kidney ratio of $2.1 \pm 0.5$ (Fig. 4A).

Inhibition of platelet-derived growth factor receptor $\beta$ (PDGFR $\beta$ ) in tumor stroma (pericytes of neovasculature and cancer-associated fibroblasts) normalizes tumor interstitial pressure and improves drug uptake and efficacy. An anti-PDGFR $\beta$-Affibody molecule, DOTA-Z09591, was labeled with ${ }^{68} \mathrm{Ga}$ and evaluated as a potential companion diagnostic (31). In mice, ${ }^{68} \mathrm{Ga}$-DOTA-Z09591 provided clear visualization of U-87 MG xenografts (36,000 PDGFR $\beta$ receptors per cell) at $2 \mathrm{~h}$ after injection (Fig. 4B).

To evaluate PD-L1 expression before programmed death 1- or PD-L1-targeting therapy and for response monitoring, a PD-L1-specific Affibody molecule with a dissociation constant of $1 \mathrm{nM}$ was selected (32). This NOTA-conjugated $\mathrm{Z}_{\mathrm{PD}-\mathrm{L} 1 \_1}$ was labeled with ${ }^{18} \mathrm{~F}$ using ${ }^{18} \mathrm{~F}-\mathrm{AlF} .{ }^{18} \mathrm{~F}-\mathrm{AlF}-\mathrm{NOTA}-\mathrm{Z}_{\mathrm{PD}-\mathrm{L} 1 \_1}$ enabled specific imaging of PD-L1 in murine models, with a tumor-to-blood ratio exceeding values obtained using radiolabeled antibodies several days after injection (Fig. 4B).

\section{PRECLINICAL STUDIES WITH OTHER PROTEIN SCAFFOLDS}

\section{Knottins}

Inhibitor cystine knots, also known as knottin peptides, are small polypeptides consisting of 30-50 amino acids with a molecular weight of about $4 \mathrm{kDa}$. They are characterized by their structural motif with 3 cystine bridges, forming a knot, and can be found in a wide range of animals, plants, and fungi (3).

Kimura et al. reported a knottin peptide that binds to $\alpha_{v} \beta_{6}$, an integrin overexpressed in many cancers. It demonstrated fast and specific tumor targeting in mice bearing $\alpha_{v} \beta_{6}$-expressing tumors. However, low tumor-to-liver, tumorto-kidney, and tumor-to-gut ratios were also observed (33).

Jiang et al. reported the potential use of a $7 \mathrm{C}$ knottin peptide as a SPECT probe for imaging of integrin $\alpha_{\mathrm{v}} \beta_{3}$-positive 
tumors. Despite the fact that no SPECT imaging data were shown, a biodistribution study on mice revealed fast and specific accumulation of ${ }^{111}$ In-labeled $7 \mathrm{C}$ in $\alpha_{\mathrm{v}} \beta_{3}$-positive human subcutaneously growing U87MG glioblastoma at $0.5 \mathrm{~h}$ after injection (34).

More recently, the ${ }^{18} \mathrm{~F}$-labeled divalent integrin $\alpha_{\mathrm{v}} \beta_{3^{-}}$ targeting knottin peptide 3-4A, containing 2 separate integrinbinding paratopes, was evaluated in subcutaneously growing U87MG xenografts (35). Images revealed clear uptake in tumors after $30 \mathrm{~min}$, with low background signal, except in kidneys (Fig. 5B).

\section{DARPins}

DARPins are scaffold proteins with a size of 14-18 kDa, which are derived from natural ankyrin repeat proteins. Synthetic DARPin libraries have been designed to select DARPins against different targets, mainly for nonradioactive therapeutic applications (3).

Goldstein et al. described SPECT imaging of HER2 expression using ${ }^{125} \mathrm{I}-/{ }^{111} \mathrm{In}$-labeled G3 DARPin (Fig. 5A). High tumor uptake was measured for both radionuclides in mice bearing human BT474 HER2-positive xenografts at $4 \mathrm{~h}$ after injection. However, the lower uptake of ${ }^{111} \mathrm{In}$-compound in normal tissues led to higher tumor-to-background ratios than for its ${ }^{125}$ I counterpart (36).

\section{FN3 Scaffolds}

A small anti-CD20 receptor protein based on the $10-\mathrm{kDa}$ human FN3 has been generated for PET imaging of B-cell lymphomas (37). ${ }^{64} \mathrm{Cu}$-DOTA$\mathrm{FN} 3_{\mathrm{CD} 20}$ was evaluated in

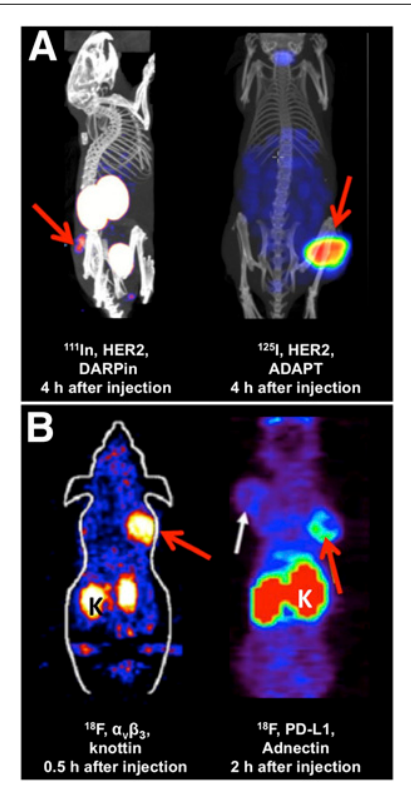

FIGURE 5. SPECT/CT $(\mathrm{A})$ and $\mathrm{PET} / \mathrm{CT}$ (B) imaging using engineered scaffold protein-based tracers in mice, showing uptake in positive tumor models (arrows). (Adapted from $(35,36,38,40)$.) $\mathrm{K}=$ kidney. this compound is being tested in a single-center substudy of the CheckMate 511 clinical trial (NCT02714218/EudraCT 2015-004920-67) to evaluate its potential as a biomarker in metastatic melanoma patients (38).

\section{ADAPTs}

ADAPTs use a 46-amino-acid scaffold of an albuminbinding domain $(5.2 \mathrm{kDa})$ of streptococcal protein $\mathrm{G}$. The anti-HER2 ADAPT6 was selected for its high-affinity binding $(1.1 \mathrm{nM})$ and its loss of binding to albumin to facilitate fast blood clearance. ADAPT6 was site-specifically DOTAconjugated at the $\mathrm{N}$ terminus (39). ${ }^{111} \mathrm{In} /{ }^{68} \mathrm{Ga}-\mathrm{DOTA}-$ ADAPT6 showed high uptake in SKOV-3 xenografts, and as soon as $1 \mathrm{~h}$ after injection, PET enabled clear discrimination between xenografts with high and low expression. Reabsorption of ADAPT6 in the kidneys was high and could not be reduced using injection of cationic amino acids or Gelofusine (Hausmann Laboratories Ltd.). Further studies demonstrated that targeting properties of ADAPTs might be appreciably improved by modification of labeling chemistry and $\mathrm{N}$ terminus composition. An optimized ${ }^{111}$ In-labeled variant, DOTA-Cys ${ }^{59}$-ADAPT6, had a tumor-to-blood ratio of $277 \pm 35$ at $4 \mathrm{~h}$ after injection. Use of the nonresidualizing ${ }^{125}$ I-HPEM label provided a tumor-to-kidney ratio of $13 \pm 3$, opening a way for radionuclide therapy (Fig. 5A) (40).

The radiolabeling chemistry might influence the properties of targeting proteins by modifying critical amino acids or the local charge and lipophilicity of the protein surface. This might affect on-target and off-target interactions, excretion, and intracellular retention of the radionuclide after internalization (41). In this way, changes in radiolabeling chemistry might have important effects on the imaging contrast obtained and optimal imaging time point. Therefore, a meticulous optimization of labeling chemistry is crucial for high-sensitivity imaging using small proteins.

\section{CONCLUSION}

sdAbs and Affibody proteins have clinically confirmed the safety, low radiation exposure, and high potential of molecular imaging in cancer patients. Although studies with larger patient cohorts are required to establish their exact clinical value, the early-phase data for HER2-specific probes are encouraging. Also, several emerging sdAb- and scaffold protein-based probes that target other clinically relevant targets have been developed preclinically, and their clinical translation may impact future patient care.

\section{DISCLOSURE}

Marleen Keyaerts has received travel and accommodation expenses from Bayer NV. Nick Devoogdt and Matthias D'Huyvetter are cofounders of CamelIDs. Nick Devoogdt has received funding from Boehringer-Ingelheim, Complix. Ahmet Krasniqi, Marleen Keyaerts, Nick Devoogdt, and Matthias D'Huyvetter have patents on sdAb imaging and 
therapy. Fredrik Frejd is an employee of Affibody AB. Fredrik Frejd, Anna Orlova, and Vladimir Tolmachev have patents on Affibody development and applications. Ahmet Krasniqi has a doctoral grant from Agentschap Innoveren \& Ondernemen (IWT.141388); Marleen Keyaerts is a senior clinical investigator; and Matthias D'Huyvetter is a postdoctoral fellow of the Research Foundation-Flanders (FWO). Research was funded by CancerPlan Action (Federal Public Service Health, Food Chain Safety, and Environment, Belgium), Kom-op-tegen-Kanker, FWO, Swedish Cancer Society, and Swedish Research Council. No other potential conflict of interest relevant to this article was reported.

\section{REFERENCES}

1. Lamberts LE, Williams SP, Terwisscha van Scheltinga AG, et al. Antibody positron emission tomography imaging in anticancer drug development. J Clin Oncol. 2015;33:1491-1504.

2. Hudson PJ, Souriau C. Engineered antibodies. Nat Med. 2003;9:129-134.

3. Simeon R, Chen Z. In vitro-engineered non-antibody protein therapeutics. Protein Cell. 2018;9:3-14.

4. De Vos J, Devoogdt N, Lahoutte T, Muyldermans S. Camelid single-domain antibody-fragment engineering for (pre)clinical in vivo molecular imaging applications: adjusting the bullet to its target. Expert Opin Biol Ther. 2013;13:11491160 .

5. Miao Z, Levi J, Cheng Z. Protein scaffold-based molecular probes for cancer molecular imaging. Amino Acids. 2011;41:1037-1047.

6. Xavier C, Vaneycken I, D'Huyvetter M, et al. Synthesis, preclinical validation, dosimetry, and toxicity of ${ }^{68} \mathrm{Ga}$-NOTA-anti-HER2 Nanobodies for iPET imaging of HER2 receptor expression in cancer. J Nucl Med. 2013;54:776-784.

7. Keyaerts M, Xavier C, Heemskerk J, et al. Phase I study of ${ }^{68} \mathrm{Ga}-\mathrm{HER} 2-$ Nanobody for PET/CT assessment of HER2 expression in breast carcinoma. J Nucl Med. 2016;57:27-33.

8. Xavier C, Blykers A, Vaneycken I, et al. ${ }^{18} \mathrm{~F}$-nanobody for PET imaging of HER2 overexpressing tumors. Nucl Med Biol. 2016;43:247-252.

9. D'Huyvetter M, De Vos J, Xavier C, et al. ${ }^{131}$ I-labeled anti-HER2 camelid sdAb as a theranostic tool in cancer treatment. Clin Cancer Res. 2017;23:6616-6628.

10. Vaidyanathan G, McDougald D, Choi J, et al. Preclinical evaluation of ${ }^{18} \mathrm{~F}-$ labeled anti-HER2 Nanobody conjugates for imaging HER2 receptor expression by immuno-PET. J Nucl Med. 2016;57:967-973.

11. Pruszynski M, Koumarianou E, Vaidyanathan G, et al. Targeting breast carcinoma with radioiodinated anti-HER2 Nanobody. Nucl Med Biol. 2013;40:52-59.

12. Pruszynski M, Koumarianou E, Vaidyanathan G, et al. Improved tumor targeting of anti-HER2 Nanobody through $N$-succinimidyl 4-guanidinomethyl-3-iodobenzoate radiolabeling. J Nucl Med. 2014;55:650-656.

13. Evazalipour M, D’Huyvetter M, Tehrani BS, et al. Generation and characterization of nanobodies targeting PSMA for molecular imaging of prostate cancer. Contrast Media Mol Imaging. 2014;9:211-220.

14. Chatalic KL, Veldhoven-Zweistra J, Bolkestein M, et al. A novel ${ }^{111}$ In-labeled anti-prostate-specific membrane antigen Nanobody for targeted SPECT/CT imaging of prostate cancer. J Nucl Med. 2015;56:1094-1099.

15. Krasniqi A, D'Huyvetter M, Xavier C, et al. Theranostic radiolabeled anti-CD20 $\mathrm{sdAb}$ for targeted radionuclide therapy of non-Hodgkin lymphoma. Mol Cancer Ther. 2017;16:2828-2839.

16. Movahedi K, Schoonooghe S, Laoui D, et al. Nanobody-based targeting of the macrophage mannose receptor for effective in vivo imaging of tumor-associated macrophages. Cancer Res. 2012;72:4165-4177.

17. Blykers A, Schoonooghe S, Xavier C, et al. PET imaging of macrophage mannose receptor-expressing macrophages in tumor stroma using ${ }^{18} \mathrm{~F}$-radiolabeled Camelid single-domain antibody fragments. J Nucl Med. 2015;56:1265-1271.

18. Broos K, Keyaerts M, Lecocq Q, et al. Non-invasive assessment of murine PD-L1 levels in syngeneic tumor models by nuclear imaging with nanobody tracers. Oncotarget. 2017;8:41932-41946.

19. Ingram JR, Dougan M, Rashidian M, et al. PD-L1 is an activation-independent marker of brown adipocytes. Nat Commun. 2017;8:647.
20. Sörensen J, Sandberg D, Sandstrom M, et al. First-in-human molecular imaging of HER2 expression in breast cancer metastases using the ${ }^{111}$ In-ABY-025 affibody molecule. J Nucl Med. 2014;55:730-735.

21. Sörensen J, Velikyan I, Sandberg D, et al. Measuring HER2-receptor expression in metastatic breast cancer using $\left[{ }^{68} \mathrm{Ga}\right] \mathrm{ABY}-025$ Affibody PET/CT. Theranostics. 2016;6:262-271.

22. Sandström M, Lindskog K, Velikyan I, et al. Biodistribution and radiation dosimetry of the anti-HER2 Affibody molecule ${ }^{68} \mathrm{Ga}-\mathrm{ABY}-025$ in breast cancer patients. J Nucl Med. 2016;57:867-871.

23. Sandberg D, Tolmachev V, Velikyan I, et al. Intra-image referencing for simplified assessment of HER2-expression in breast cancer metastases using the Affibody molecule ABY-025 with PET and SPECT. Eur J Nucl Med Mol Imaging. 2017;44:1337-1346.

24. Altai M, Wallberg H, Honarvar H, et al. ${ }^{188}$ Re-ZHER2:V2, a promising affibodybased targeting agent against HER2-expressing tumors: preclinical assessment. J Nucl Med. 2014;55:1842-1848.

25. Altai M, Perols A, Tsourma M, et al. Feasibility of Affibody-based bioorthogonal chemistry-mediated radionuclide pretargeting. J Nucl Med. 2016;57:431-436.

26. Honarvar H, Westerlund K, Altai M, et al. Feasibility of Affibody molecule-based PNA-mediated radionuclide pretargeting of malignant tumors. Theranostics. 2016;6:93-103.

27. Nahta R, Yu D, Hung MC, Hortobagyi GN, Esteva FJ. Mechanisms of disease: understanding resistance to HER2-targeted therapy in human breast cancer. Nat Clin Pract Oncol. 2006;3:269-280.

28. Orlova A, Hofstrom C, Strand J, et al. $\left[{ }^{99 \mathrm{~m}} \mathrm{Tc}(\mathrm{CO})_{3}\right]^{+}-(\mathrm{HE})_{3}-\mathrm{Z}_{\mathrm{IGF} 1 \mathrm{R}: 4551}$, a new Affibody conjugate for visualization of insulin-like growth factor-1 receptor expression in malignant tumours. Eur J Nucl Med Mol Imaging. 2013;40: 439-449.

29. Rosestedt M, Andersson KG, Mitran B, et al. Affibody-mediated PET imaging of HER3 expression in malignant tumours. Sci Rep. 2015;5:15226.

30. Garousi J, Honarvar H, Andersson KG, et al. Comparative evaluation of Affibody molecules for radionuclide imaging of in vivo expression of carbonic anhydrase IX. Mol Pharm. 2016;13:3676-3687.

31. Strand J, Varasteh Z, Eriksson O, Abrahmsen L, Orlova A, Tolmachev V. Gallium-68-labeled affibody molecule for PET imaging of PDGFRbeta expression in vivo. Mol Pharm. 2014;11:3957-3964.

32. Gonzalez Trotter DE, Meng X, McQuade P, et al. In vivo imaging of the programmed death ligand 1 by ${ }^{18}$ F PET. J Nucl Med. 2017;58:1852-1857.

33. Kimura RH, Teed R, Hackel BJ, et al. Pharmacokinetically stabilized cystine knot peptides that bind alpha-v-beta-6 integrin with single-digit nanomolar affinities for detection of pancreatic cancer. Clin Cancer Res. 2012;18:839-849.

34. Jiang L, Miao Z, Kimura RH, et al. ${ }^{111}$ In-labeled cystine-knot peptides based on the Agouti-related protein for targeting tumor angiogenesis. J Biomed Biotechnol. 2012;2012:368075.

35. Jiang L, Kimura RH, Ma X, et al. A radiofluorinated divalent cystine knot peptide for tumor PET imaging. Mol Pharm. 2014;11:3885-3892.

36. Goldstein R, Sosabowski J, Livanos M, et al. Development of the designed ankyrin repeat protein (DARPin) G3 for HER2 molecular imaging. Eur J Nucl Med Mol Imaging. 2015;42:288-301.

37. Natarajan A, Hackel BJ, Gambhir SS. A novel engineered anti-CD20 tracer enables early time PET imaging in a humanized transgenic mouse model of B-cell non-Hodgkins lymphoma. Clin Cancer Res. 2013;19:6820-6829.

38. Donnelly DJ, Smith RA, Morin P, et al. Synthesis and biological evaluation of a novel ${ }^{18} \mathrm{~F}$-labeled Adnectin as a PET radioligand for imaging PD-L1 expression. J Nucl Med. 2018;59:529-535.

39. Garousi J, Lindbo S, Nilvebrant J, et al. ADAPT, a novel scaffold protein-based probe for radionuclide imaging of molecular targets that are expressed in disseminated cancers. Cancer Res. 2015;75:4364-4371.

40. Lindbo S, Garousi J, Mitran B, et al. Radionuclide tumor targeting using ADAPT scaffold proteins: aspects of label positioning and residualizing properties of the label. J Nucl Med. 2018;59:93-99.

41. Tolmachev V, Orlova A. Influence of labelling methods on biodistribution and imaging properties of radiolabelled peptides for visualisation of molecular therapeutic targets. Curr Med Chem. 2010;17:2636-2655.

42. Dijkers EC, Oude Munnink TH, Kosterink JG, et al. Biodistribution of ${ }^{89} \mathrm{Zr}$ trastuzumab and PET imaging of HER2-positive lesions in patients with metastatic breast cancer. Clin Pharmacol Ther. 2010;87:586-592.

43. Garousi J, Andersson KG, Dam JH, et al. The use of radiocobalt as a label improves imaging of EGFR using DOTA-conjugated Affibody molecule. Sci Rep. 2017;7:5961. 